\title{
Nanocomposites of Polyamide 6/residual Monomer with Organic-modified Montmorillonite and their Nanofibers Produced by Electrospinning
}

\author{
Cesar Augusto Gonçalves Beatrice, Camila Ribeiro dos Santos, \\ Marcia Cristina Branciforti, Rosario Elida Suman Bretas* \\ Department of Materials Engineering, Federal University of São Carlos - UFSCar, \\ Rod. Washington Luís, Km 235, CP 676, CEP 13565-905, São Carlos, SP, Brazil
}

Received: March 16, 2012; Revised: May 5, 2012

\begin{abstract}
Nanocomposites of an organic-modified montmorillonite (MMT) and polyamide 6 (PA6) with a residual monomer were produced by melt mixing in a torque rheometer. By wide angle X-rays diffraction (WAXD), intercalated/exfoliated structures were observed in the PA6/MMT nanocomposites with 3 and 5 wt. (\%) of MMT; on the other hand, when 7 wt. (\%) of MMT was added, a nanocomposite with exfoliated structures was obtained due to the predominant linking reactions between the residual monomer and the "nanoclays" organic surfactant. Solutions of these PA6/MMT nanocomposites at 15,17 and 20 wt. (\%) in formic acid were prepared. The 3 and 5 wt. (\%) nanocomposites were successfully electrospun; however, electrospinning of the $7 \mathrm{wt}$. (\%) nanocomposite was not possible. WAXD, scanning and transmission electron microscopy results showed that the 3 and 5 wt. (\%) nanofibers with average diameter between $80-250 \mathrm{~nm}$ had exfoliated structures. These results indicate that the high elongational forces developed during the electrospinning process changed the initial intercalated/exfoliated structure of the nanocomposites to an exfoliated one.
\end{abstract}

Keywords: electrospinning, nanocomposites, polyamide 6, residual monomer, nanoclay

\section{Introduction}

A number of processing techniques such as drawing, template synthesis, phase separation, self-assembly, electrospinning etc. have been used to prepare polymer nanofibers, all with its advantages and disadvantages ${ }^{1}$. Electrospinning has been recognized as one of the most efficient process for the fabrication of polymer nanofibers. Various polymers have been successfully electrospun in recent years mostly in solvent solution and some in melt form. When the diameter of the polymer fibers decrease from micrometer scale to nanometer scales, several characteristics such as very large surface area to volume ratio, high porosity, flexibility in surface functionalities and superior mechanical performance surge. These better properties make the polymer nanofibers and the electrospinning process optimal candidates for the development of new materials with various applications like textile, filters, drug delivery systems, scaffolds for tissue engineering, reinforcement materials, supports for enzymes or catalysts, optical and electric applications, sensors, and so on ${ }^{2,3}$.

Many researchers have incorporated inorganic materials into the polymer nanofibers; the majority of these filled polymer nanofibers exhibit better properties than the unfilled polymers or the conventional microcomposites ${ }^{4,5}$.

*e-mail: bretas@ufscar.br
Nanoclays as montmorillonite (MMT) are one of these inorganic materials; MMT is an aluminous silicate mineral with sodium ions present between the clay layers, which has attracted great interest due to the improvement in mechanical, thermal, barrier and flame-retardant properties of the polymeric matrix by the use of only a small amount of MMT (1-10 wt. (\%)) .

Polyamide 6 (PA6) is a semicrystalline polymer with high fatigue strength, low friction coefficient, enhanced toughness and high resistance to a wide spectrum of oils, chemicals and fuels ${ }^{6}$. Many reports on PA6 and MMT composite nanofibers obtained by electrospinning have been published $\mathrm{d}^{7-9}$. For example, in order to improve catalysis effect and thermal stability of PA6 nanocomposites, Fe-MMT, in which the $\mathrm{Al}^{3+}$ ions were replaced by $\mathrm{Fe}^{3+}$ ions in the octahedral crystal lattice of the MMT, has been used $^{10}$. The majority of the studies focus on the method of their preparation, morphology, structural characterization, mechanical and thermal properties as well as processing. The study of Fong et al. ${ }^{7}$ showed that the electrospinning process resulted in highly aligned and exfoliated MMT layers and PA6 crystallites. However, the addition of a few percent of $\mathrm{N}, \mathrm{N}$-dimethyl formamide to the solution resulted in agglomeration of the MMT in the fibers. The addition of MMT, the rapid solvent removal and the ultra-large draw 
ratio of electrospinning favored the formation of polyamides $\gamma$-phase crystallites. Regarding the crystal structures of PA6 and PA6/clay fibers, Yoon et al. ${ }^{8}$ verified that the annealing increased the $\gamma$-crystalline form of both fibers, and its effect was dominant in the PA6/clay fiber. On drawing, the $\gamma$-crystalline form was easily converted into the $\alpha$-form in the pure PA6 nanofibers, whereas it was still observed at a relatively high spin-draw ratio in the PA6/clay fibers. However, although the $\alpha$-crystal form was dominant in PA6, the $\gamma$-crystal form was dominant in PA6/clay with annealing and drawing. They also verified the fast crystallization rate of PA6/clay compared with pure PA6. The reinforcing effect of clay was also observed: the initial modulus of PA6/clay fiber was $30 \%$ higher than the neat PA6 fiber. Li et al. ${ }^{9}$ demonstrated that nanocomposite fibers with good dispersion and exfoliation of MMT in PA6 were obtained by melt-extrusion in a twin-screw extruder prior to dissolving in formic acid for electrospinning. They also showed that the mechanical properties of the electrospun fibers depended not only on the MMT content but also on the fibers sizes. Smaller fibers exhibited higher Young's modulus.

The role of a small amount of residual monomer in the PA6 has been tested in our research group. Results from our laboratories ${ }^{11}$ have shown that if a masterbatch between an organic MMT, which surfactant has hydroxyl groups (Cloisite ${ }^{\circledR}$ 30B) and the PA6 with residual monomer is done, the hydroxyls groups of the surfactant react with the amine groups of the polyamide and an exfoliated PA6/MMT nanocomposite is obtained. In this work, a PA6 with residual monomer was chosen as the matrix of nanocomposites with an organic treated MMT which were sequentially electrospun to produce nanofibers.

\section{Experimental}

\subsection{Materials}

An extrusion grade of PA6, Technyl C 402M from Rhodia Engineering Plastics, was chosen as matrix of the nanocomposites. This grade had residual monomer (0.60 wt. (\%)), density of $1.14 \mathrm{~g} . \mathrm{cm}^{-3}$, melting temperature of $222{ }^{\circ} \mathrm{C}$, melt flow index of $2.5 \mathrm{~g} / 10 \mathrm{~min}\left(235^{\circ} \mathrm{C} / 2.16 \mathrm{~kg}\right)$, a concentration of carboxyl terminal groups of $35 \mathrm{mEq} . \mathrm{kg}^{-1}$, and a concentration of amine terminal groups also of $35 \mathrm{mEq} \cdot \mathrm{kg}^{-1}$. In our earlier work ${ }^{11}$, it was shown that the residual monomer acted as a branching agent. The nanoclay was an organically modified montmorillonite (MMT), Cloisite $^{\circledR}$ 30B (C30B), from Southern Clay Products Inc; the modification was done with a surfactant, a quaternary ammonium salt, which has unsaturated aliphatic chains with two hydroxyl groups, named di-ethanol-methyl-tallow quaternary ammonium salt. The cation exchange capacity of this nanoclay was $900 \mathrm{mEq} \cdot \mathrm{kg}^{-1}$ of nanoclay. Its density was $0.36 \mathrm{~g} . \mathrm{cm}^{-3}$ and its original galleries distance was $1.87 \mathrm{~nm}$. The solvent was aqueous formic acid with $85 \%$ purity, from Synth.

\subsection{Preparation of the nanocomposites}

The PA6 and MMT were dried at $80{ }^{\circ} \mathrm{C}$ for 14 hours under vacuum prior to use, the quantity of residual monomer was maintained. PA6/MMT nanocomposites with 3, 5 and 7 wt. (\%) of C30B nanoclay (designed as N3, N5 and N7 samples, respectively) were produced by melt blending in a Haake Rheomix 600p torque rheometer using roller rotors, temperature of $250{ }^{\circ} \mathrm{C}$ and rotors velocity $\mathrm{N}$ of $120 \mathrm{rpm}$ during 4 minutes. This last temperature and residence time were chosen based in results of thermogravimetric analysis (TGA) previously published ${ }^{11,12}$, in which it was observed that the nanoclays surfactant was stable up to approximately $275^{\circ} \mathrm{C}$. Both, polymer and nanoclay were fed at once; the total mass was $50 \mathrm{~g}$ (70\% chamber filling). Pellets of the pure PA6 were also processed in this torque rheometer under the same mixing conditions of the nanocomposites, producing the sample designed as PA6.

\subsection{Preparation of the electrospinning solutions}

The electrospinning solutions of PA6 and PA6/MMT nanocomposites were prepared at 15, 17 and 20 wt. (\%) of nanocomposite concentration by dissolving the melt blending nanocomposites in formic acid at $40{ }^{\circ} \mathrm{C}$ and stirring for 4 hours.

\subsection{Conditions of the electrospinning process}

The electrospinning of the solutions was done at controlled temperature and humidity $\left(27 \pm 2{ }^{\circ} \mathrm{C}\right.$ and $50 \pm 5 \%$, respectively) in an equipment constituted by a high voltage supply Bertan model 210-30R, a cylindrical collector with rotation of $20 \mathrm{rpm}$, covered with aluminum foil and grounded, a $20 \mathrm{~mL}$ glass syringe with a Hamilton needle with $1.2 \mathrm{~mm}$ inner diameter and $30 \mathrm{~mm}$ length and a copper electrode. The setup the electrospinning apparatus was reported in our previous work ${ }^{13}$. During the solutions electrospinning, two different electrical fields were used: 2.5 and $5.0 \mathrm{kV} \cdot \mathrm{cm}^{-1}$. After electrospinning, all the nanofibers were vacuum dried at $40{ }^{\circ} \mathrm{C}$ for 24 hours.

\subsection{Characterization}

The extent of clay intercalation/exfoliation of the PA6/MMT nanocomposites before and after electrospinning was made by wide angle $\mathrm{x}$-ray diffraction (WAXD) using a diffractometer from Siemens model D5000 with CuK $\alpha$ radiation $(\lambda=1.5458 \AA$ ) operating at $40 \mathrm{kV}$ and $40 \mathrm{~mA}$. Samples were scanned between $2 \theta=0.6$ and $10^{\circ}$ at a rate of $1 \% \mathrm{~min}$. Measurements were recorded at each $0.02^{\circ}$.

Morphological characterization of the nanofibers was done in a field emission scanning electron microscope (FEG-SEM) from Philips, model XL-30. The SEM samples were coated with gold and observed under $20 \mathrm{kV}$ accelerating voltage. Analyses of transmission electron microscopy (TEM) were done in a Philips, model CM120, operating at $120 \mathrm{kV}$. In order to investigate the dispersion of organoclay in the electrospun fibers, the fibers were directly electrospun onto $\mathrm{Cu}$ grids covered with an ultra-thin carbon layer The average fiber diameter $(\mathrm{Fd})$ of approximately 100-120 fibers per sample was calculated using the Image Pro-Plus 3.0 software. 
The zero $\left(\eta_{0}\right)$ and steady state $(\eta)$ shear viscosities of the nanocomposites and electrospinning solutions were measured using a strain-controlled rheometer ARES, from Rheometric Scientific as a function of the shear rate $(\gamma)$. The measurements were carried out using parallel-plate geometry for the melt samples, with plates diameter of $25 \mathrm{~mm}$, gap between plates of $1 \mathrm{~mm}$, under nitrogen atmosphere, at $250{ }^{\circ} \mathrm{C}$ and Couette geometry for the solutions, with gap between cylinders of $1 \mathrm{~mm}$, at room temperature. The shear storage modulus G' and the shear loss modulus G' were measured as a function of angular frequency $\omega$ (between 0.01 and $100 \mathrm{rad} / \mathrm{s}$ ) and time (at a constant $\omega$ of $1.0 \mathrm{rad} / \mathrm{s}$ ) during 4000 seconds in the same controlled strain rheometer. Before the rheological measurements, the polymer and the nanocomposite samples were vacuum dried at $80{ }^{\circ} \mathrm{C}$ for 14 hours.

The solutions electrical conductivities (K) were measured in a conductimeter from Digimed, model DM-31, with a Pt electrode. The solutions' surface tensions $(\tau)$ were measured by the du Nöy method using a Krüss tensionmeter, model K6, with a Pt ring.

\section{Results and Discussions}

\subsection{Characterization of the melt blending nanocomposites}

Figure 1 shows the curves of torque versus time for PA6 and PA6/MMT nanocomposites (N3, N5 and N7) during mixing, at $250{ }^{\circ} \mathrm{C}$. The maximum torque in the PA6 $(69.3 \mathrm{Nm})$ was lower than in the nanocomposites $(76.6 \mathrm{Nm}$ for the N3 and $82.2 \mathrm{Nm}$ for the N5 and N7 samples), as expected. The torque decreased after the melting peak, attaining stabilization after approximately 2.4 minutes. The minimum energy for mixing (E) was calculated from the total torque (TTQ) from the following relation ${ }^{14}$ :

$$
E=(2 \pi N) T T Q
$$

where $\mathrm{N}$ is the rotational speed. The calculated $\mathrm{E}$ was 34,000 N.m for the PA6, 35,100 Nm for the N3, 36,000 Nm for the N5 and 37,600 N.m for the N7 sample. That is, as the amount of nanoclay increased in the mixture, the energy for mixing also increased, as expected.

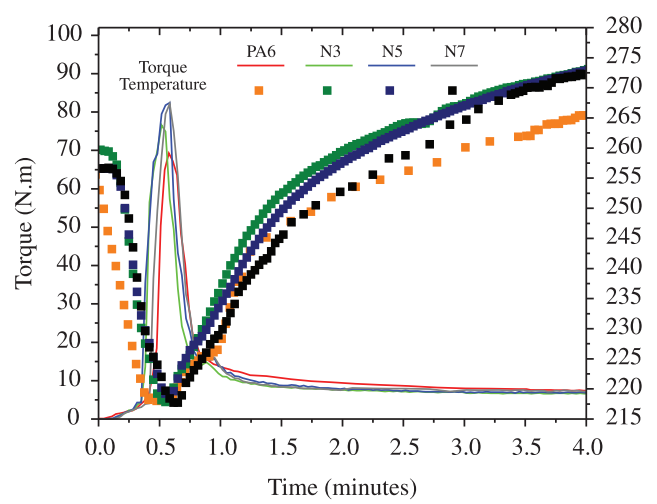

Figure 1. Torque as a function of time for PA6 and PA6/MMT nanocomposites (N3, N5 and N7) samples, at $250{ }^{\circ} \mathrm{C}$.
While the PA6 melt attained a final temperature of $265{ }^{\circ} \mathrm{C}$, the nanocomposites developed temperatures up to $273{ }^{\circ} \mathrm{C}$. The temperatures during the mixing of the pure PA6 were the lowest, probably because the branching reactions within the PA6 promoted by the residual monomer were not highly exothermic. On the other hand, the temperatures of the nanocomposites during the whole mixing were higher than of the PA6. However, the N7 composition had a temperature increase lower than the other two nanocomposites; for example after 2.5 minutes, the $\mathrm{N} 7$ composition was at $260^{\circ} \mathrm{C}$, while the N5 and N3 were approximately at $265^{\circ} \mathrm{C}$. In the $\mathrm{N} 7$ nanocomposite due to the higher amount of nanoclay and surfactant, reactions between the residual monomer and the surfactant predominately took place, which helped to better disperse the nanoclay within the PA6; with a better dispersion, the viscous heating and increase of temperature were lower. In the N5 and N3 nanocomposites, due to the smaller amount of nanoclay, the reactions between the residual monomer and the nanoclay surfactant were less intense; as a result, dispersion was worse and an increase in temperature was observed mainly due to the increase in viscous heating promoted by the nanoclays tactoids. Results of infrared spectroscopy confirmed the linking reactions between the amine groups of the residual monomer and the hydroxyls groups of the nanoclays organic surfactant in the nanocomposites. These results were not presented in this article. Certainly, the preferential reactions between the residual monomer and the nanoclays surfactant will influence the intercalation/exfoliation degree of the nanocomposites.

The WAXD diffractograms of the pure nanoclay (MMT) and of the PA6/MMT nanocomposites (N3, N5 and N7) are shown in Figure 2. It can be observed that the nanoclays main diffraction peak occurred at $2 \theta=4.8\left(\mathrm{~d}_{001}=1.9 \mathrm{~nm}\right)$. In the diffraction curves of the $\mathrm{N} 7$ nanocomposite this peak disappeared, showing that the nanoclays lamellae were exfoliated and randomly distributed in the polymer. The polar groups of the PA6 residual monomer formed strong interactions with the polar surfactant of the nanoclay, allowing the penetration of the PA6 molecules

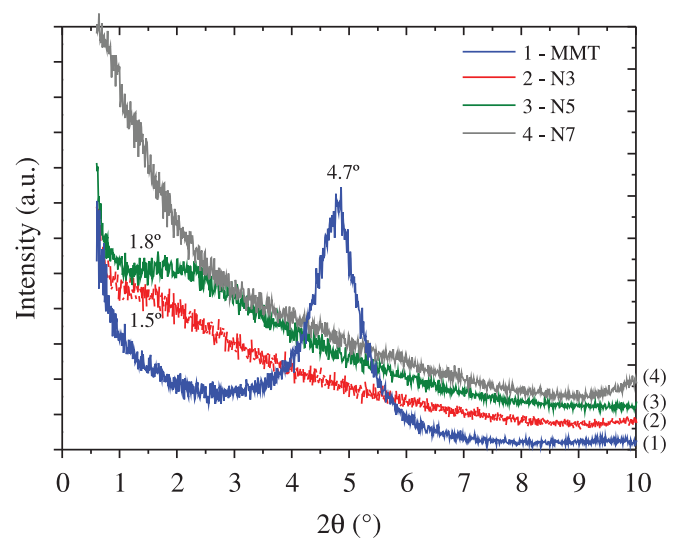

Figure 2. WAXD diffractograms of the pure nanoclay and PA6/MMT nanocomposites (N3, N5 and N7) prepared in the torque rheometer. 
into the galleries of the nanoclay, forming thus exfoliated structures. However, in the N5 and N3 nanocomposites this peak was shifted to $2 \theta=1.8^{\circ}(\mathrm{N} 5)$ and $2 \theta=1.5^{\circ}(\mathrm{N} 3)$, respectively, indicating the increase of the montmorillonite galleries distance and that both samples had a simultaneous intercalated/exfoliated structure. Therefore, the preferential reactions between the residual monomer and the nanoclay surfactant in the N7 sample allowed the development of an exfoliated structure, as already predicted by the torque measurements.

The results of the steady state shear viscosity $(\eta(\gamma))$ of the PA6 and PA6/MMT nanocomposites prepared in the Haake rheometer at low shear rates, at $250^{\circ} \mathrm{C}$, are shown in Figure 3.

The viscosity of the PA6 displayed a large Newtonian plateau, while the nanocomposites N3 and N5 had a smaller Newtonian plateau. The N7 sample behaves as a Bingham fluid, confirming the formation of an exfoliated network in this composition. The increase in the amount of nanoclay increased the pseudoplasticity of the nanocomposites, as given by the value of $n$ in the Power Law model of viscosity $\left(\eta=m \gamma^{\mathrm{n}-1}\right)$, where $\mathrm{m}$ is the consistency. These values were $0.67,0.57$ and 0.43 for the N3, N5 and N7 nanocomposites, respectively.

This result indicates that 7 wt. (\%) of MMT was the amount of MMT which was closer to the percolation limit of these nanocomposites; the N7 sample developed a percolated structure formed as a result of the physical and chemical interactions (pseudo-entanglements) between the macromolecular chains and the nanoclays lamellae, enhanced by the reactions between the residual monomer and the nanoclays surfactant. The percolated network will have, therefore, a higher flow resistance than the pure polymer.

Figure 4 shows the dynamic rheological properties of these materials, at $250{ }^{\circ} \mathrm{C}$, where $\mathrm{G}^{\prime}(\omega)$ is the shear storage modulus and G" $(\omega)$ the shear loss modulus as a function of the frequency $\omega$.

It can be observed that both modules increased proportionally with the increase in the amount of nanoclay, as confirmed by other works ${ }^{11,12}$. Analyzing the terminal zone, it is observed that the PA6 sample had the standard

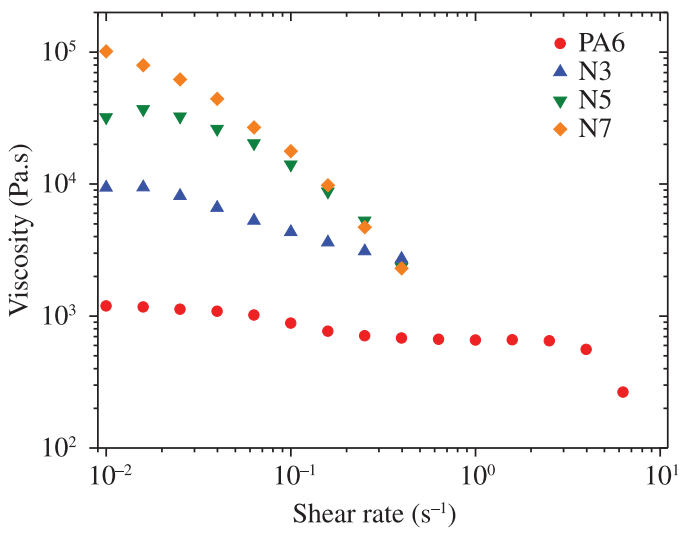

Figure 3. Steady state shear viscosity of PA6 and PA6/MMT nanocomposites (N3, N5 and N7) samples, at $250{ }^{\circ} \mathrm{C}$. behavior of a polymer melt (G" > G') with the typical slopes of a polymer melt $\left(G^{\prime} \sim \omega^{2}\right.$ and $\left.G^{\prime \prime} \sim \omega^{1}\right)$. However, with the increase of nanoclay, the $G^{\prime}(\omega)$ slope changed to lower values $\left(G^{\prime} \sim \omega^{1}\right)$, whereas the $G^{\prime \prime}(\omega)$ slope changed to values near $0\left(G^{\prime \prime} \sim \omega^{0}\right)$. As Zhao et al. ${ }^{15}$ pointed out, when two crossing points appear on the viscoelastic curves of a given composition, this composition will be lower than the percolation threshold; thus, 3 wt. (\%) of MMT was lower than the percolation threshold for these nanocomposites. The nanocomposite $\mathrm{N} 3$ shows two crossover frequencies $\left(\omega_{c}\right)$, Figure 4; the polymer relaxation time $\left(\mathrm{t}_{\mathrm{r}}\right)$ is inversely proportional to the crossover frequency. Thus, it was observed that the $\mathrm{N} 3$ sample had lower relaxation times than the N5 and N7 samples. That is, the N3 sample did not form a percolated network. Its lower relaxation time was due to the inter-macromolecular interactions, while its higher relaxation time was due to the presence of the nanoclays platelets. Both, the N5 and N7 samples were above the percolation threshold and behave as pseudo-solids, with $\mathrm{G}^{\prime}>\mathrm{G}$ ' at all frequencies. Table 1 shows the rheological parameters, crossover frequency $\left(\omega_{\mathrm{c}}\right)$, relaxations time $\left(\mathrm{t}_{\mathrm{r}}\right)$ and the slopes of the $G^{\prime}(\omega)$ and $G^{\prime \prime}(\omega)$ curves of the nanocomposites, at $250{ }^{\circ} \mathrm{C}$.

\subsection{Characterization of the electrospinning solutions}

Figure 5 shows the steady state shear viscosity $\left(\eta_{s}(\gamma)\right)$ of the electrospinning solutions at concentrations of 15,17 and $20 \mathrm{wt}$. (\%), respectively, at room temperature.

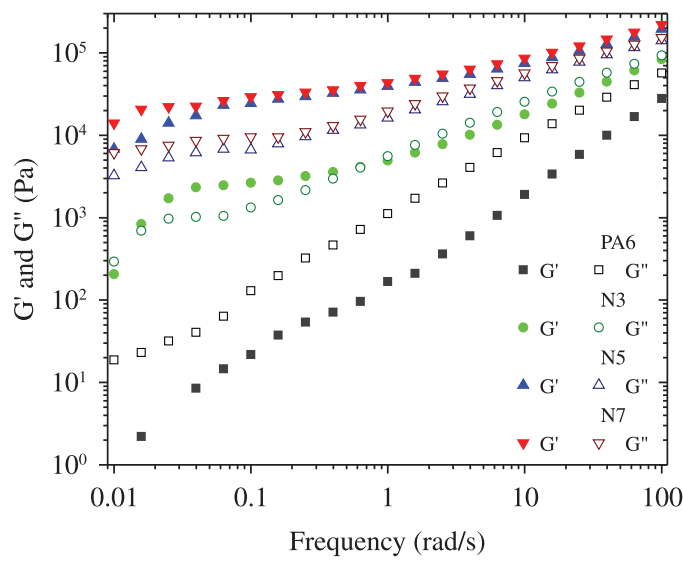

Figure 4. Dynamic rheological properties of PA6 and PA6/MMT nanocomposites (N3, N5 and N7) samples, at $250{ }^{\circ} \mathrm{C}$.

Table 1. Rheological parameters of the samples, at $250{ }^{\circ} \mathrm{C}$.

\begin{tabular}{ccccc}
\hline Material & $\begin{array}{c}\text { Crossover } \\
\text { frequency, } \\
\text { (c) (rad/s) }\end{array}$ & $\begin{array}{c}\text { Relaxation } \\
\text { time, tr } \\
(\mathbf{s})\end{array}$ & Slope, G' & Slope, G’ \\
\hline PA6 & $\rightarrow \infty$ & $\rightarrow 0$ & 1.79 & 0.89 \\
N3 & 0.02 and & 50 and & 1.55 & 0.72 \\
N5 & 0.67 & 1.50 & & 0.60 \\
N7 & $\rightarrow 0$ & $\rightarrow \infty$ & 0.97 & 0.62 \\
\hline
\end{tabular}




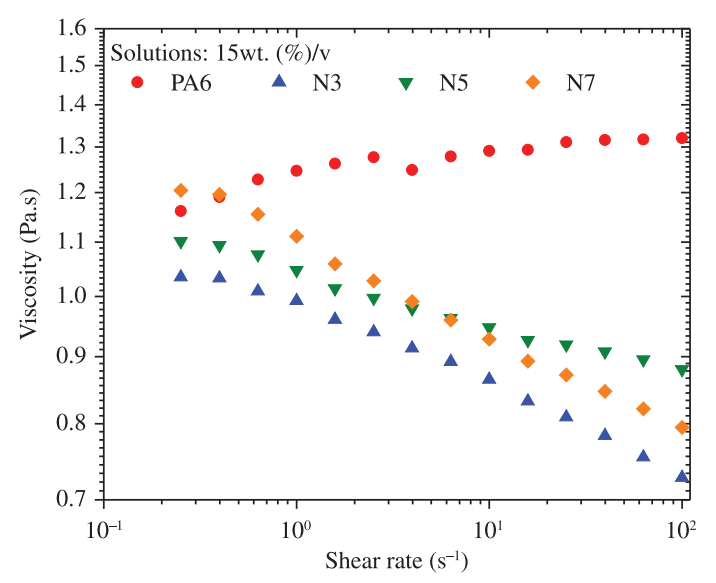

(a)

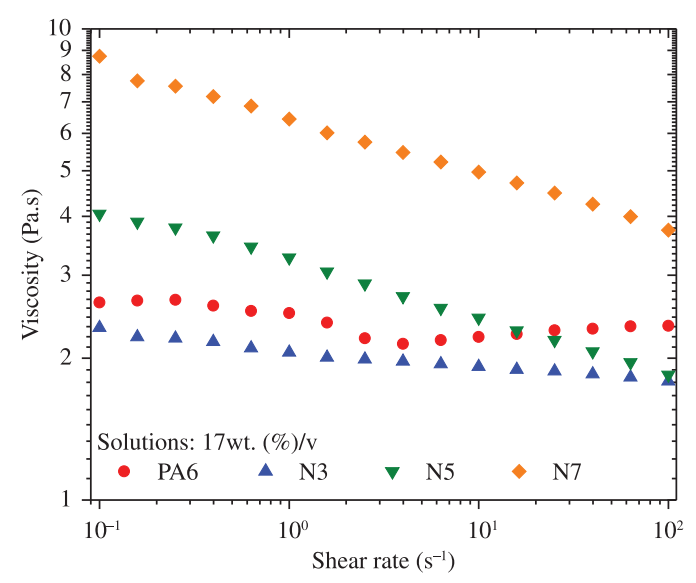

(b)

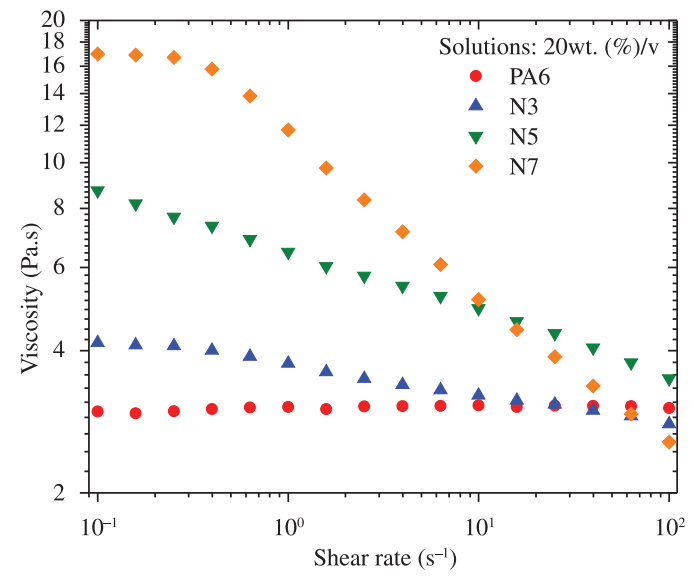

(c)

Figure 5. Steady state shear viscosity of solutions with concentrations of (a) 15, (b) 17 and (c) 20 wt. (\%) of PA6 and PA6/MMT nanocomposites, at $25^{\circ} \mathrm{C}$.

In Figure 5a (15 wt. (\%) solutions), it can be observed that the viscosity of the PA6 increased with the shear rate probably due to solvent evaporation, while the viscosities of the nanocomposites decreased, being slightly pseudoplastics, the N7 solution having the highest pseudoplasticity. The values of $n$ for the N3, N5 and N7 nanocomposites were $0.96,0.97$ and 0.93 , respectively. The solutions with 17 wt. (\%), Figure 5b, had different behavior. The pure PA6 solution was mostly Newtonian and with viscosity intermediate between the N3 and N5 compositions. Again, the nanocomposites solutions were pseudoplastics, with values of $n$ of $0.93,0.88$ and 0.86 for the N3, N5 and N7 samples, respectively. At 20 wt. (\%), Figure 5c, all the nanocomposites solutions had higher viscosities than the PA6, and the values of $n$ for the N3, N5 and N7 were 0.92 , 0.84 and 0.71 , respectively. Thus, solutions with 15 wt. (\%) concentration will require careful control of the solvent evaporation, while solutions with $20 \mathrm{wt}$. (\%) concentration will require higher electrical tensions to flow.

Table 2 shows the solutions properties as a function of MMT and solution concentration. The applied electrical field during the electrospinning is also listed in Table 2 .
The $\eta_{0}$ of all solutions (PA6, N3, N5 and N7 solutions) increased with increasing solution concentration (15, 17 and 20 wt. (\%)), as expected. It can also be observed in Table 2 that the electrical conductivity of the solutions decreased with the increase of the solution concentration and increased with the increase of MMT content. The surface tension of all the solutions was between 41 and $42 \mathrm{mN} \cdot \mathrm{m}^{-1}$. Similar results were also observed by $\mathrm{Li}$ et al. ${ }^{9}$ for the same type of solutions. They found electrical conductivity values between 4.3 and $4.9 \mathrm{mS} \mathrm{cm}^{-1}$ and surface tension values between 41 and $42 \mathrm{mN} \cdot \mathrm{m}^{-1}$ for PA6/formic acid solutions and PA6/5 wt. (\%) C30B formic acid solutions, respectively, with concentrations of 15 and 20 wt. (\%). Santos et al. ${ }^{16,17}$ produced nanofibers of polyamide 66 with 2, 3 and $4 \mathrm{wt}$. (\%) $\mathrm{C} 30 \mathrm{~B}$ by melt mixing following by electrospinning of the solutions, these solutions showed electrical conductivity and surface tension in the range of $2.9-3.8 \mathrm{mS}^{-\mathrm{cm}^{-1}}$ and $38-45 \mathrm{mN} . \mathrm{m}^{-1}$, respectively. Guerrini et al. ${ }^{18}$ also found electrical conductivity values between 4.3 and $4.9 \mathrm{mS} . \mathrm{cm}^{-1}$ and surface tension values between 37 and $45 \mathrm{mN} \cdot \mathrm{m}^{-1}$ for polyamide $66 /$ formic acid solutions with concentrations of 10, 15, 17 and 20 wt. (\%). 
Table 2. Solution properties, applied electrical field and fiber diameter.

\begin{tabular}{|c|c|c|c|c|c|c|c|}
\hline Sample & $\begin{array}{c}\text { MMT } \\
(\text { wt. }(\%))\end{array}$ & $\begin{array}{c}\text { Concentration } \\
\text { (wt. }(\%))\end{array}$ & $\eta$ 0 (Pa.s) & $\mathrm{K}(\mathrm{mS} / \mathrm{cm})$ & $\tau(\mathbf{m N} / \mathbf{m})$ & $\begin{array}{c}\text { Electrical } \\
\text { field }(\mathrm{kV} / \mathrm{cm})\end{array}$ & Fd (nm) \\
\hline \multirow{6}{*}{ PA6 } & \multirow{2}{*}{-} & \multirow{2}{*}{15} & \multirow{2}{*}{1.24} & \multirow{2}{*}{3.39} & \multirow{2}{*}{41} & 2.5 & $156 \pm 17$ \\
\hline & & & & & & 5.0 & $171 \pm 21$ \\
\hline & \multirow{2}{*}{-} & \multirow{2}{*}{17} & \multirow{2}{*}{2.65} & \multirow{2}{*}{3.07} & \multirow{2}{*}{41} & 2.5 & $220 \pm 28$ \\
\hline & & & & & & 5.0 & $284 \pm 32$ \\
\hline & \multirow{2}{*}{-} & \multirow{2}{*}{20} & \multirow{2}{*}{2.97} & \multirow{2}{*}{2.88} & \multirow{2}{*}{42} & 2.5 & $296 \pm 34$ \\
\hline & & & & & & 5.0 & $322 \pm 39$ \\
\hline \multirow{6}{*}{$\mathrm{N} 3$} & \multirow{2}{*}{3} & \multirow{2}{*}{15} & \multirow{2}{*}{0.97} & \multirow{2}{*}{3.44} & \multirow{2}{*}{41} & 2.5 & $90 \pm 18$ \\
\hline & & & & & & 5.0 & $110 \pm 24$ \\
\hline & \multirow{2}{*}{3} & \multirow{2}{*}{17} & \multirow{2}{*}{2.32} & \multirow{2}{*}{3.19} & \multirow{2}{*}{42} & 2.5 & $143 \pm 30$ \\
\hline & & & & & & 5.0 & $223 \pm 34$ \\
\hline & \multirow{2}{*}{3} & \multirow{2}{*}{20} & \multirow{2}{*}{4.16} & \multirow{2}{*}{2.91} & \multirow{2}{*}{42} & 2.5 & $217 \pm 42$ \\
\hline & & & & & & 5.0 & $246 \pm 48$ \\
\hline \multirow{6}{*}{ N5 } & 5 & 15 & 107 & 357 & 41 & 2.5 & $83 \pm 16$ \\
\hline & 5 & 15 & 1.07 & 3.51 & & 5.0 & $97 \pm 18$ \\
\hline & 5 & 17 & 405 & 340 & 47 & 2.5 & $127 \pm 21$ \\
\hline & 3 & 17 & 4.03 & 5.49 & 42 & 5.0 & $172 \pm 30$ \\
\hline & 5 & 20 & 819 & 326 & 42 & 2.5 & $198 \pm 30$ \\
\hline & & & & & & 5.0 & $215 \pm 36$ \\
\hline & 7 & 15 & 120 & 369 & 42 & 2.5 & - \\
\hline & I & 15 & 1.20 & 3.09 & 42 & 5.0 & - \\
\hline N7 & 7 & 17 & 875 & 357 & 42 & 2.5 & - \\
\hline 1) & I & 17 & 8.15 & 3.51 & 42 & 5.0 & - \\
\hline & 7 & 20 & 1689 & 339 & 42 & 2.5 & - \\
\hline & I & 20 & 10.89 & 3.39 & 42 & 5.0 & - \\
\hline
\end{tabular}

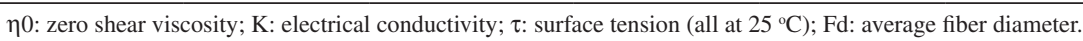

\subsection{Characterization of the electrospinning nanofibers}

Homogeneous nanofibers of the PA6 and PA6/MMT nanocomposites were prepared from the PA6, N3 and N5 solutions at all concentrations. The electrospinning of the N7 solution at all concentrations and electrospinning conditions did not produce nanofibers.

Figures 6 to 8 show the FEG-SEM micrographs of the electrospun nanofibers from the PA6, N3 and N5 solutions, respectively. The non-woven mats are formed of nanofibers with diameters between 83 and $322 \mathrm{~nm}$, randomly distributed. The average fiber diameters $(\mathrm{Fd})$ of each sample are also listed in Table 2. It is observed that the lower the concentration of the solution (or the viscosity), the lower was the diameter of the nanofibers.

The micrographs indicated that the increase in nanoclay content in the solutions decreased the nanofibers diameters, probably due to the increase in electrical conductivity. Regarding the influence of the applied electrical field on the nanofibers diameter, it was observed that the higher the applied electrical field, the higher the PA6 and PA6/MMT nanofibers diameters. The micrographs also showed the formation of very fine fibers, such as in Figure $6 \mathrm{~b}$, which are formed probably due to instability of electrically charged liquid jets of polymer solutions.

Others reports about the production of PA6 and PA6/MMT nanofibers by electrospinning have found similar results. Fong et al. ${ }^{7}$, for example, produced nanofibers of PA6 and PA6/MMT with diameters between 100 and $500 \mathrm{~nm}$ using 1,1,1,3,3,3-hexa-fluoro-2-propanol (HFIP) and a mixture of HFIP and N,N-dimethyl formamide as solvent. Li et al. ${ }^{9}$ obtained electrospun PA6 fibers with diameters of $120 \mathrm{~nm}$ and PA6/MMT nanofibers with diameters between 70 and $140 \mathrm{~nm}$, both from formic acid solutions. They concluded that lower solutions concentration and higher solutions conductivity favored thinner fibers. Cai et al. ${ }^{10}$ electrospun PA6/formic acid solution and PA6/Fe-MMT in DMF/formic acid solution and obtained electrospun PA6 fibers with diameters from several tens of nanometers to $100 \mathrm{~nm}$ and more uniform PA6/Fe-MMT fibers with $50 \mathrm{~nm}$ of diameter.

Typical WAXD diffraction patterns of the pure nanoclay and of some N3 and N5 electrospun fibers produced at different processing conditions (Table 2) are shown in Figure 9. In the diffraction curves of the N3 and N5 electrospun fibers no diffraction peak corresponding to the (001) plane reflection of the nanoclay was observed. That is, the nanoclay was exfoliated and well dispersed in both N3 and N5 nanofibers. All studied nanofibers showed similar WAXD diffraction patterns. As described before, both nanocomposites had intercalated and exfoliated structures at the same time after mixing in the Haake rheometer; therefore, it seems that the high elongational forces of the electrospinning process promoted exfoliation of the nanoclay on these nanocomposites. Therefore, it can be 
$2.5 \mathrm{kV} . \mathrm{cm}^{-1}$

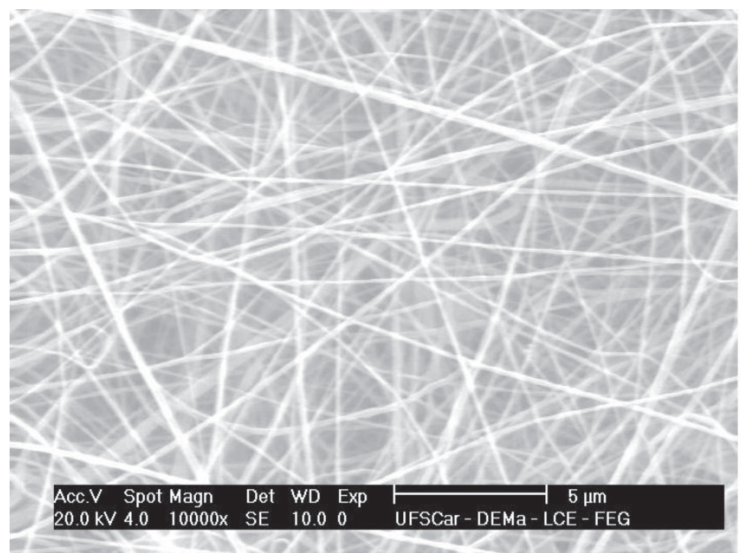

(a)
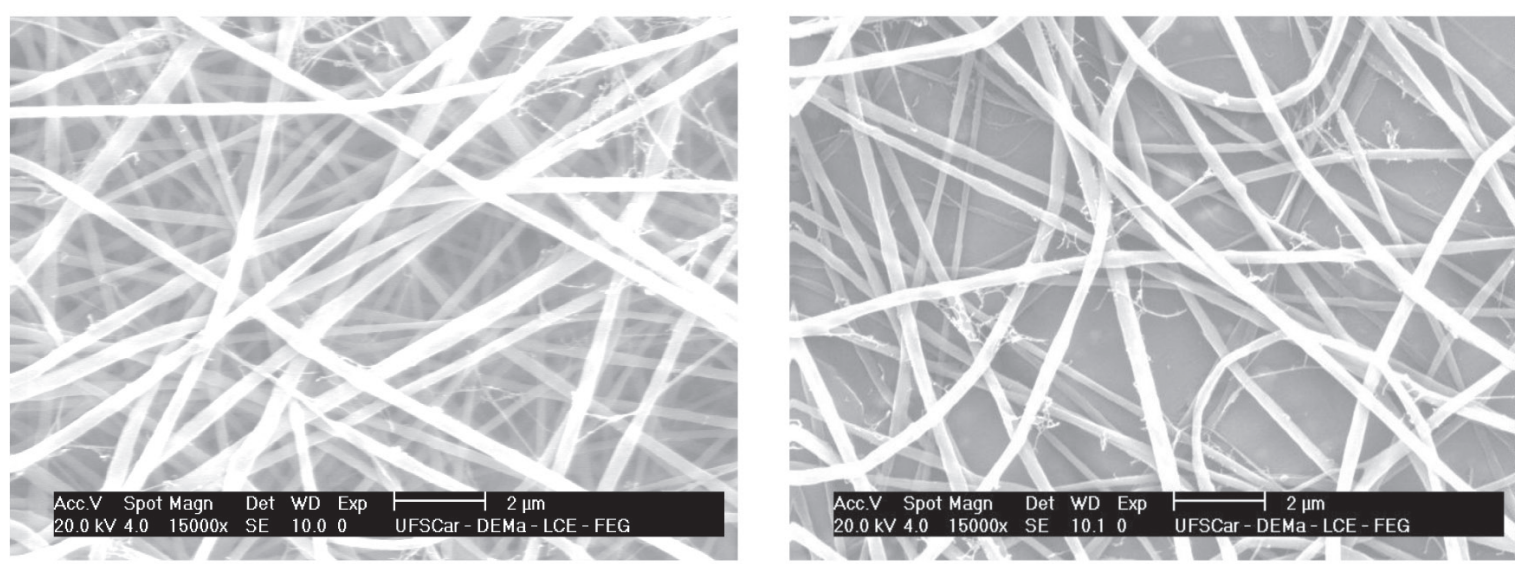

(b)
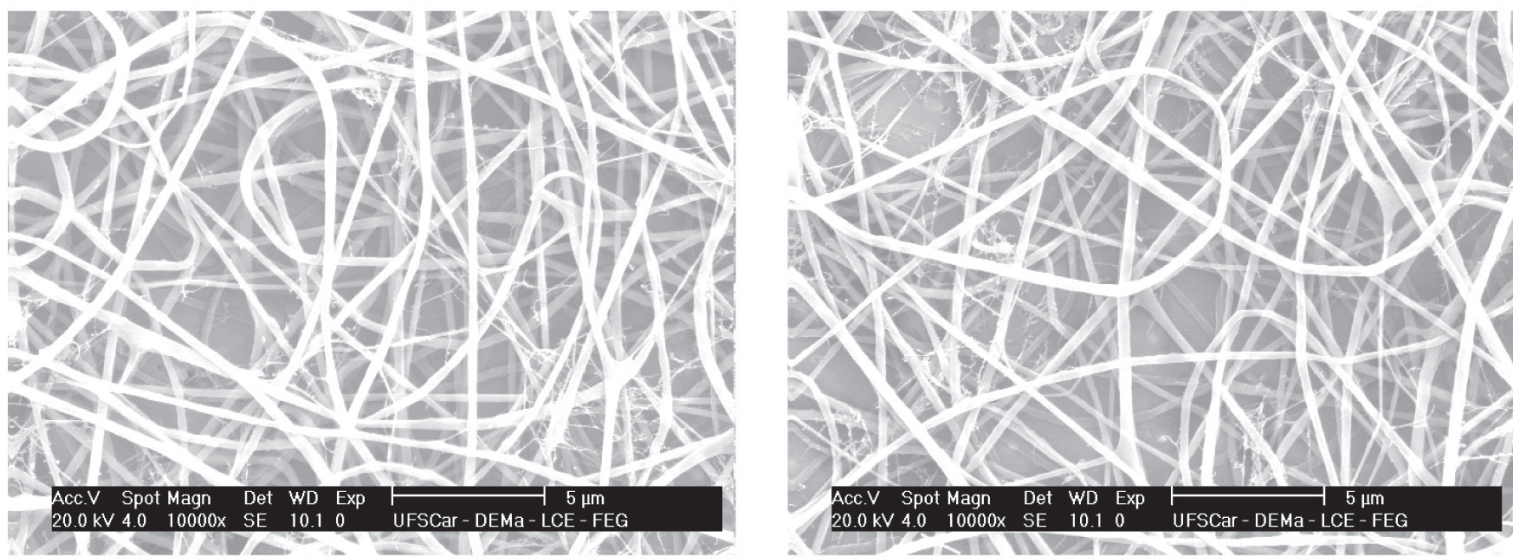

(c)

Figure 6. FE-SEM images of the electrospun fibers from PA6 solutions with concentration of (a) 15, (b) 17 and (c) 20 wt. (\%) at 2.5 and $5.0 \mathrm{kV} . \mathrm{cm}^{-1}$. 
$2.5{\mathrm{kV} . \mathrm{cm}^{-1}}^{-1}$

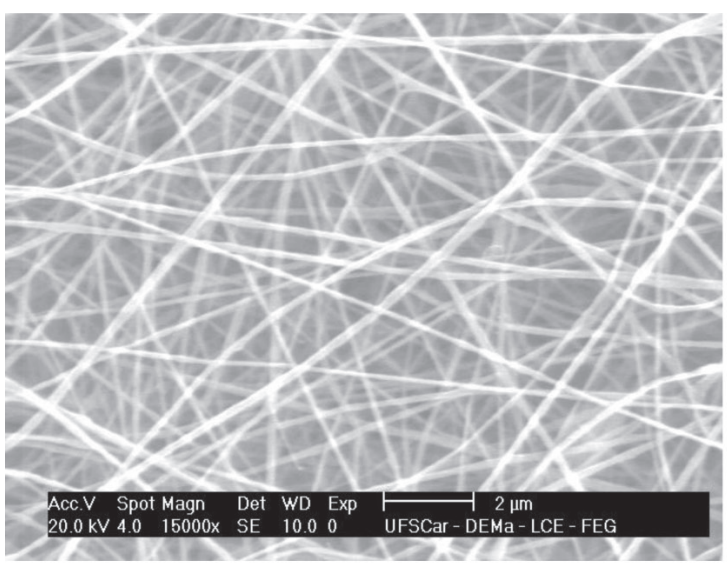

$5.0 \mathrm{kV} . \mathrm{cm}^{-1}$

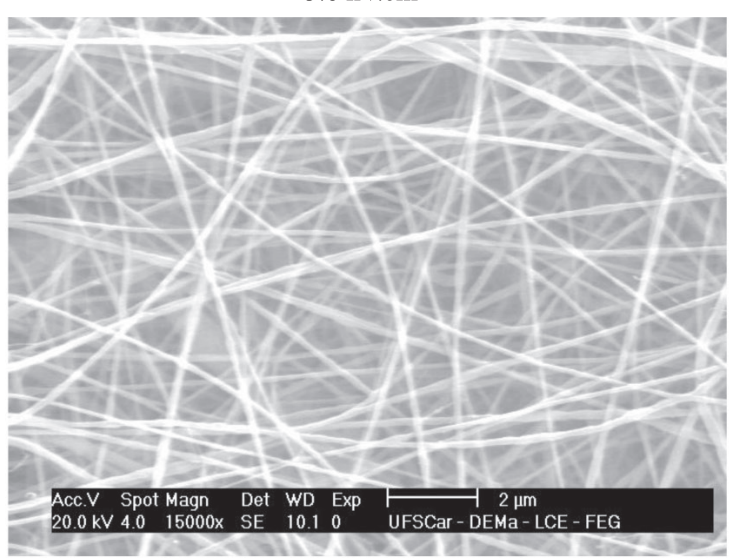

(a)

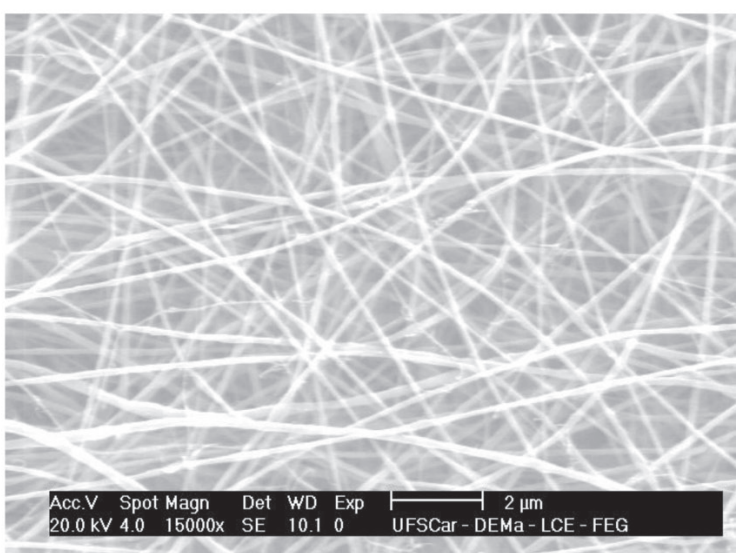

(b)
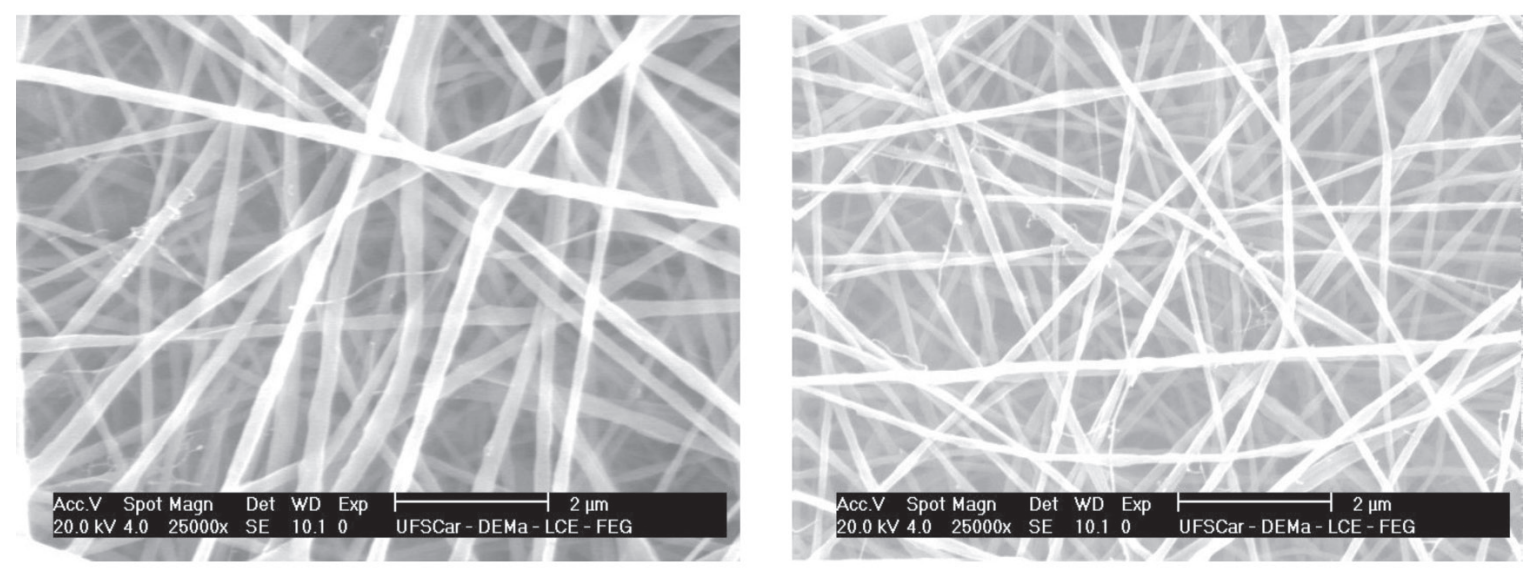

(c)

Figure 7. FE-SEM images of the electrospun fibers from N3 solutions with concentration of (a) 15 , (b) 17 and (c) 20 wt. (\%) at 2.5 and $5.0 \mathrm{kV} . \mathrm{cm}^{-1}$. 
$2.5 \mathrm{kV} . \mathrm{cm}^{-1}$

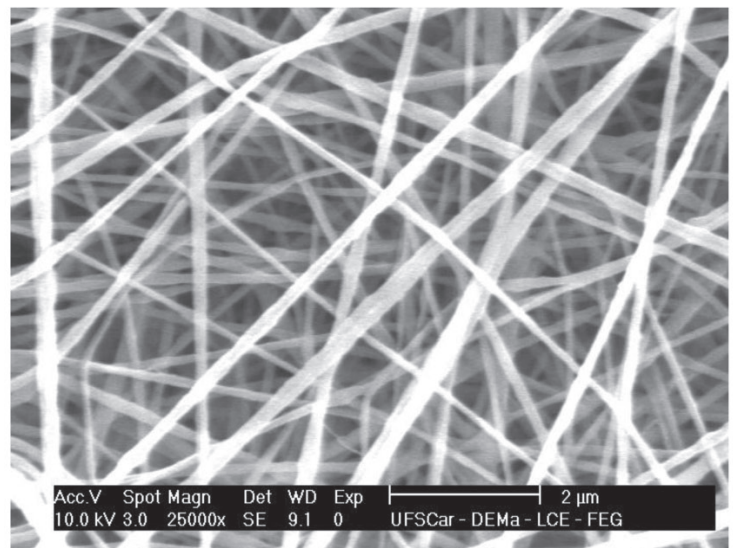

- $10.0 \mathrm{kV} 3.0 \quad 25000 \times$ SE 9.10

CO
$5.0 \mathrm{kV} \mathrm{cm}^{-1}$

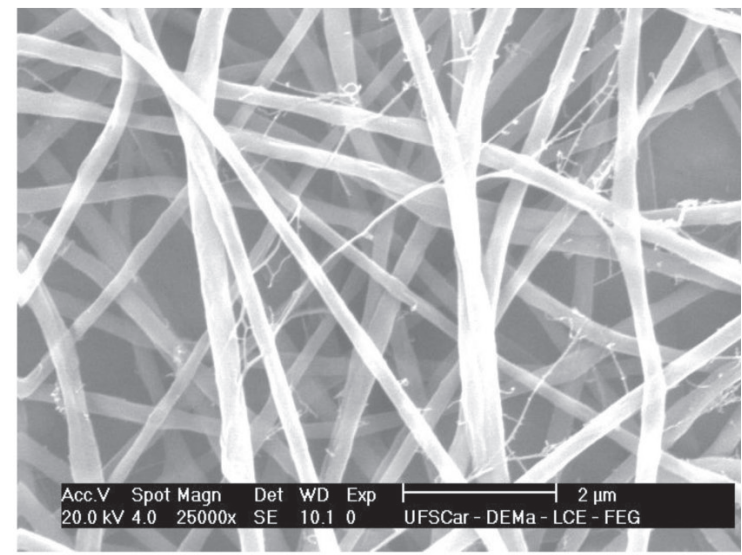

(a)
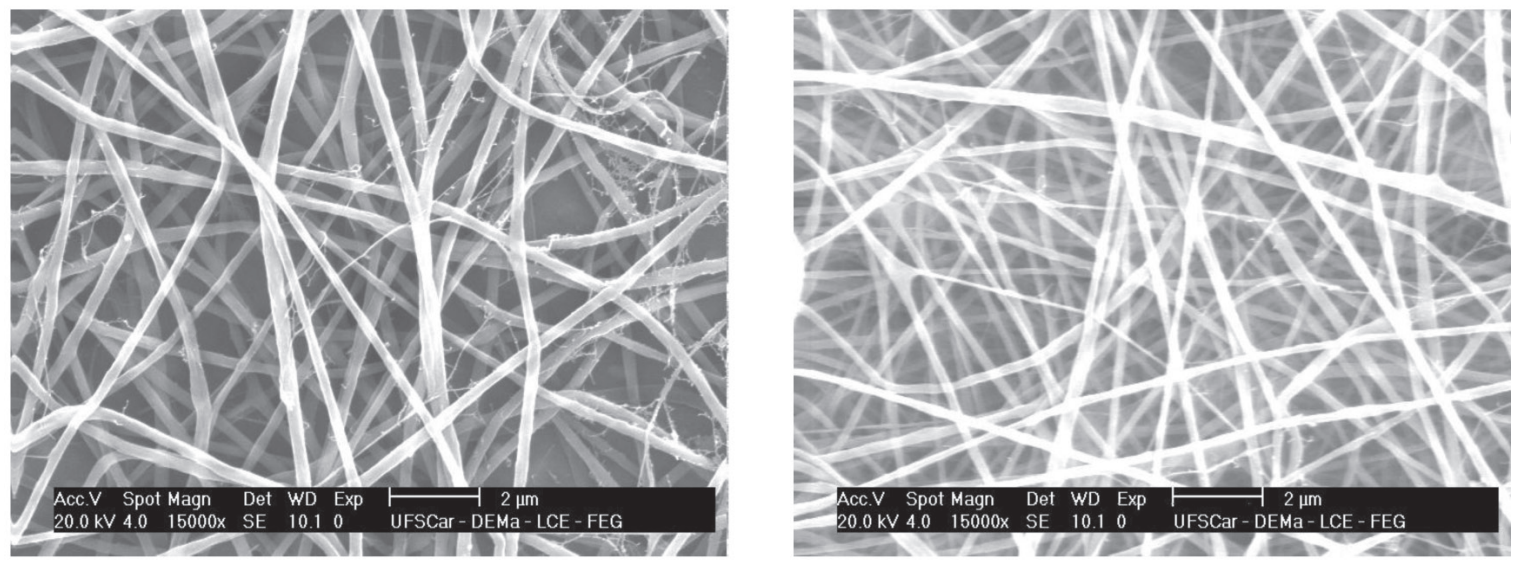

(b)
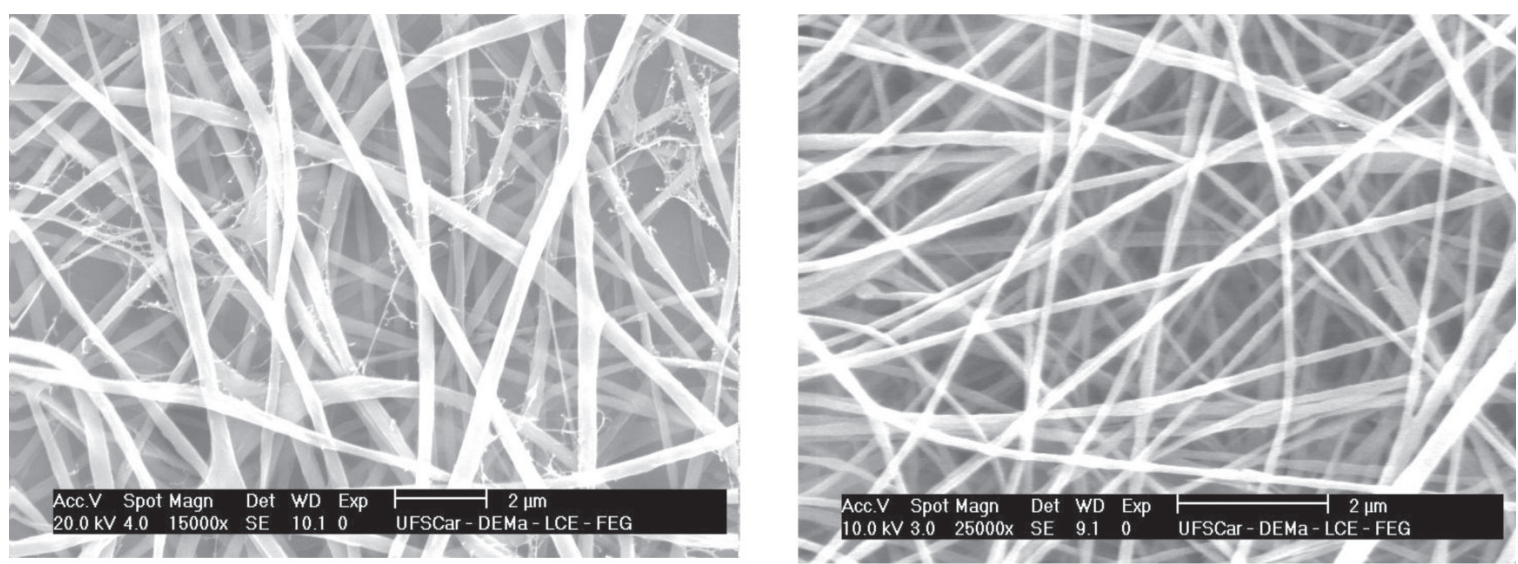

(c)

Figure 8. FE-SEM images of the electrospun fibers from N5 solutions with concentration of (a) 15, (b) 17 and (c) 20 wt. (\%) at 2.5 and $5.0 \mathrm{kV} . \mathrm{cm}^{-1}$. 


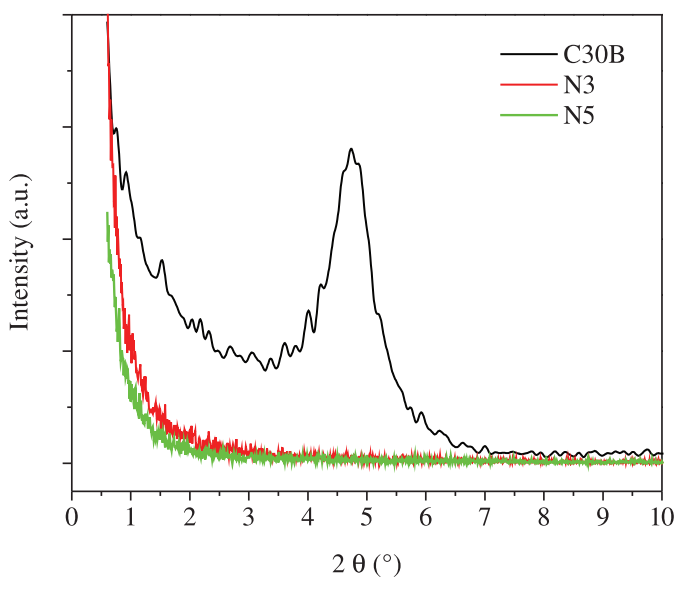

Figure 9. WAXD diffractograms of the pure nanoclay (C30B) and of the electrospun nanofibers of the PA6/MMT nanocomposites (N3 and N5). concluded that even if intercalated/exfoliated structures are developed during the melt mixing, they can be converted into exfoliated structures by the electrospinning process.

To further confirm the dispersion of nanoclay in the electrospun nanofibers, TEM investigations were done. Figure 10a shows TEM micrographs of the N3 nanofibers while Figure 10b shows of the N5 nanofibers, at different concentrations and applied electrical field. These results confirm that the exfoliated structure take place.

The TEM images show dark lines which are the MMT lamellas of thickness of approximately $1 \mathrm{~nm}$, exfoliated and oriented along the fibers main direction. This alignment is also due the action of the extensional forces produced by the electrospinning process. Thus, the exfoliated morphology was present in both N3 and N5 nanofibers. From TEM results, Yoon et al. ${ }^{8}$ observed that the nanoclays were better dispersed in the electrospun PA6/MMT fibers than in the pristine PA6/MMT sample.
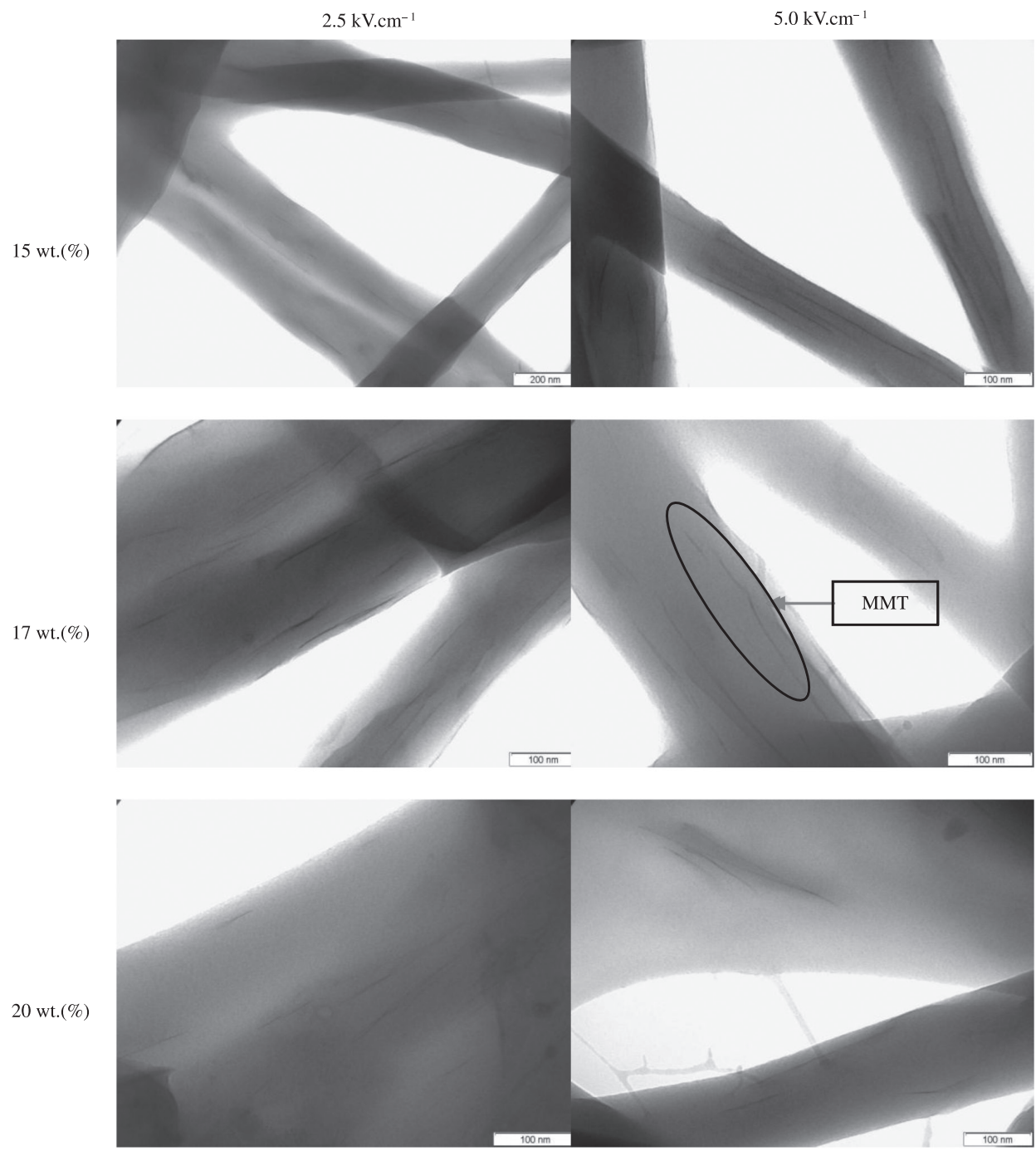

(a)

(b)

Figure 10. TEM images of the electrospun nanofibers from (a) N3 and (b) N5 solutions with concentration of 15, 17 and 20 wt. (\%) at 2.5 and $5.0 \mathrm{kV} . \mathrm{cm}^{-1}$ 


\section{Conclusions}

Nanocomposites with simultaneous intercalated and exfoliated structures were obtained by melt mixing when 3 and 5 wt. (\%) of MMT were added to the PA6; however, when $7 \mathrm{wt}$ (\%) of MMT was added, exfoliated structures were obtained due to the predominant linking reactions between the residual monomer and the nanoclay surfactant. The reaction between the hydroxyls groups of the surfactant and the amine groups of the residual monomer influenced the intercalation/exfoliation degree of the nanocomposites. Nanofibers of PA6/residual monomer $/ 3$ and 5 wt. (\%) MMT nanocomposites were successfully electrospun when the melt blending nanocomposites were dissolved in formic acid; the nanofibers had average diameters between 80 and

\section{References}

1. Huang ZM, Zhang YZ, Kotaki M and Ramakrishna S. A review on polymer nanofibers by electrospinning and their applications in nanocomposites. Composites Science and Technology. 2003; 63:2223-2253. http://dx.doi.org/10.1016/ S0266-3538(03)00178-7

2. Reneker DH and Chun I. Nanometre diameter fibres of polymer, produced by electrospinning. Nanotechnology. 1996; 7:216-223. http://dx.doi.org/10.1088/0957-4484/7/3/009

3. Li D and Xia Y. Electrospinning of Nanofibers: Reinventing the Wheel?. Advanced Materials. 2004; 16:1151-1170. http:// dx.doi.org/10.1002/adma.200400719

4. Vaia RA, Ishii H and Giannelis EP. Synthesis and properties of two-dimensional nanostructures by direct intercalation of polymer melts in layered silicates. Chemistry Mater. 1993; 5:1694-1696. http://dx.doi.org/10.1021/ cm00036a004

5. Zhu J, Morgan AB, Lamelas FJ and Wilkie CA. Fire Properties of Polystyrene-Clay Nanocomposites. Chemistry Materials. 2001; 13:3774-3780. http://dx.doi.org/10.1021/ cm000984r

6. Kim GM, Michler GH, Ania F and Balta-Calleja FJ. Temperature dependence of polymorphism in electrospun nanofibres of PA6 and PA6/clay nanocomposite. Polymer. 2007; 48:4814-4823. http://dx.doi.org/10.1016/j.polymer.2007.05.082

7. Fong H, Liu W, Wang CS and Vaia R.A. Generation of electrospun fibers of nylon 6 and nylon 6-montmorillonite nanocomposite. Polymer. 2002; 43:775-780. http://dx.doi. org/10.1016/S0032-3861(01)00665-6

8. Yoon KH, Polk MB, Min BG and Schiraldi DA. Structure and property study of nylon-6/clay nanocomposite fiber. Polymer International. 2004; 53: 2072-2078. http://dx.doi.org/10.1002/ pi. 1630

9. Li L, Bellan LM, Craighead HG and Frey MW. Formation and properties of nylon- 6 and nylon-6/montmorillonite composite nanofibers. Polymer. 2006; 47:6208-6217. http://dx.doi. org/10.1016/j.polymer.2006.06.049

10. Cai Y, Li Q, Wei Q, Wu Y, Song L and Hu Y. Structures, thermal stability, and crystalline properties of polyamide6/
$250 \mathrm{~nm}$ and an exfoliated structure. The high elongational forces developed during the electrospinning process changed their initial intercalated/exfoliated structure to an exfoliated one. However using the electrospinning set up conditions, it was not possible to electrospun, the $7 \mathrm{wt}$. (\%) nanocomposite.

\section{Acknowledgements}

The authors would like to thank CNPq and FAPESP for the financial aid, Rhodia Engineering Plastics from Brazil for the PA6 donation, Prof. R Gregorio Filho for the high voltage power supply, Prof. AC Ruvolo Filho for the electrical conductivity measurements and Prof. DFS Petri for the surface tension measurements. organic-modified Fe-montmorillonite composite nanofibers by electrospinning. Journal of Materials Science. 2008; 43:6132-6138. http://dx.doi.org/10.1007/ s10853-008-2921-6

11. Beatrice CAG, Branciforti MC, Alves RMV, Bretas RES. Rheological, mechanical, optical, and transport properties of blown films of polyamide 6/residual monomer/ montmorillonite nanocomposites. Journal of Applied Polymer Science. 2010; 116:3581-3592. http://dx.doi.org/10.1002/ app. 31898

12. Beatrice CAG. Rheological characterization of nanocomposites for blown film extrusion process. Master. [Thesis]. São Carlos: Federal University of Sao Carlos; 2008.

13. Guerrini LM, Oliveira MP, Branciforti MC, Custódio TA, and Bretas RES. Thermal and structural characterization of nanofibers of poly(vinyl alcohol) produced by electrospinning. Journal of Applied Polymer Science. 2009; 112:1680-1687. http://dx.doi.org/10.1002/app.29673

14. Bretas RES and Ávila MA. Reologia de Polímeros Fundidos. São Carlos: EdUFSCar; 2005.

15. Zhao J, Morgan AB and Harris JD. Rheological characterization of polystyrene-clay nanocomposites to compare the degree of exfoliation and dispersion. Polymer. 2005; 46:8641-8660. http://dx.doi.org/10.1016/j.polymer.2005.04.038

16. Santos CR, Branciforti MC, Canova $\mathrm{T}$ and Bretas RES. Preparação e Caracterização de Nanofibras de Nanocompósitos de Poliamida 6,6 e Argila Montmorilonita. Polímeros. 2011; 21:398-408. http://dx.doi.org/10.1590/ S0104-14282011005000068

17. Branciforti MC, Bretas RES and Santos CR. Nanocomposite nanofibers obtaining involves mixing nylon in organically modified clay and subjecting resulting composite to eletrofication to obtain nanofibers of nylon nanocomposites and exfoliated. BR patent 200703280-A2. 2007.

18. Guerrini LM, Branciforti MC, Canova T and Bretas RES. Electrospinning and characterization of polyamide 66 nanofibers with different molecular weights. Materials Research. 2009; 12:181-190. http://dx.doi.org/10.1590/ S1516-14392009000200012 